\title{
Florescimento em cana-de-açúcar
}

\author{
Flowering in sugarcane
}

\author{
Rosilaine Araldi $^{{ }^{*}}$ Ferdinando Marcos Lima Silva $^{\mathrm{I}}$ Elizabeth Orika Ono $^{\mathrm{II}}$ \\ João Domingues Rodrigues ${ }^{\text {II }}$
}

\section{- REVISÃO BIBLIOGRÁFICA -}

\section{RESUMO}

O florescimento da cana-de-açúcar é um processo fisiológico complexo formado por vários estádios de desenvolvimento, e cada estádio tem a sua própria necessidade ambiental e fisiológica. Os fatores externos relacionados com o florescimento são: fotoperíodo, temperatura, umidade e radiação solar, além da fertilidade do solo. Por outro lado, os fatores internos envolvem fitocromo, hormônios, florígeno, ácidos nucleicos, dentre outros. A intensidade do processo de florescimento e as consequências na qualidade da cana-deaçúcar variam com a variedade e com o clima. A redução do volume de caldo é o principal fator no qual o florescimento interfere, resultante do aumento do teor de fibras. Como as demais Poaceae, a cana-de-açúcar floresce, frutifica e morre, garantindo a perpetuação da espécie. Dessa forma, o homem procura interferir na natureza tentando evitar o florescimento da cana-de-açúcar, seja por meio de melhoramento genético ou por meio de reguladores vegetais. Em áreas comerciais de produção de cana-de-açúcar, onde há condições ideais para o florescimento da cultura, é recomendado o uso de variedade com potencial menos florífero. E, quando não é possível esse manejo varietal, o uso de inibidores do florescimento é a melhor alternativa para evitar mais perdas no conteúdo de sacarose.

Palavras-chave: Saccharum spp., indução floral, reguladores vegetais.

\section{ABSTRACT}

The sugarcane flowering is a complex physiological process that consists of several stages of development, each stage has its physiological and environmental requisition. The external factors related to

\begin{abstract}
flowering are: photoperiod, temperature, humidity, solar radiation in addition to soil fertility. Already the internal factors involved are: phytochrome, hormones, florigene, nucleic acids, among others. The intensity of the flowering and the consequences on the quality of sugarcane vary with the variety and the climate. The reduction of the sugarcane juice is the main factor which affected by the flowering, resulting from due to the increased fiber content. As other Poaceae, the sugarcane flowers, fruit and dies, ensuring the perpetuation of the species. Thus, the man tries to interfere in nature, trying to prevent the flowering sugarcane, either through breeding or through plant growth regulators. In areas of sugarcane commercial production, where there are ideal conditions for the flowering culture, it is recommended the se of variety with lower potential of flowering. And when this varietal management is more difficult, the use of inhibitors of flowering is the best alternative to avoid more losses of sucrose content.
\end{abstract}

Key words: Saccharum spp., flowering induction, plant growth regulators.

\section{INTRODUÇÃO}

A cana-de-açúcar é uma planta que se desenvolve em forma de touceira, sendo a parte aérea formada por colmos, folhas, inflorescências, e a subterrânea formada por raízes e rizoma. A inflorescência da cana-de-açúcar é uma panícula aberta, chamada de bandeira ou flecha (MOZAMBANI et al., 2006).

IPrograma de Pós-graduação em Agricultura, Departamento de Produção Vegetal, Universidade Estadual Paulista (UNESP), Fazenda Experimental Lageado, 18610-307, Botucatu, SP, Brasil. E-mail: araldi@fca.unesp.br. *Autor para correspondência.

IIDepartamento de Botânica. Instituto de Biociência de Botucatu, UNESP, Botucatu, SP, Brasil. 
No processo de formação da inflorescência, inicialmente deve ser detectado o período em que ocorre o estímulo para que o meristema apical se modifique, deixando de produzir folhas e colmos e passando a formar a inflorescência. Esse período é de difícil definição, pois depende da cultivar, do clima da região e das mudanças que ocorrem nos anos agrícolas. Tais fatos levam a estabelecer somente os meses em que as possibilidades dos fenômenos ocorrerem são maiores (RODRIGUES, 1995). Dessa forma, no hemisfério Sul, o estímulo e a diferenciação meristemática para a formação da flor ocorrerão nos meses de fevereiro, março e abril, dando-se o florescimento nos meses de abril, maio e junho (HUMBERT, 1974).

A cana-de-açúcar, assim como as demais Poaceae, floresce, frutifica e morre, garantindo a perpetuação da espécie. A floração é fenômeno normal e indispensável para a sobrevivência da espécie, mas não interessa ao produtor. Dessa forma, o homem procura interferir na natureza, tentando evitar o florescimento da cana-de-açúcar, seja por meio de melhoramento genético ou por meio de reguladores vegetais, sendo necessário conhecer alguns fatores básicos que controlam o florescimento da cana-deaçúcar, desde a sua fisiologia, como os fatores do meio (RODRIGUES, 1995).

O florescimento da cana-de-açúcar é controlado por um complexo de fatores, envolvendo, principalmente, o fotoperíodo, a temperatura, a umidade e a radiação solar (CASTRO, 2001), além da maturidade da planta e da fertilidade do solo (FARIAS et al., 1987). A interação entre esses fatores pode aumentar, manter ou prevenir a transformação do ápice da cana-de-açúcar de crescimento vegetativo para reprodutivo (DUNKELMAN \& BLANCHARD, 1974). O processo de florescência em si é bastante complexo, envolvendo fitocromo, hormônios, florígeno, ácidos nucléicos e fatores diversos, conforme CASTRO (1993).

Fatores que influenciam o florescimento

Fatores externos: fotoperíodo

O fotoperíodo é um dos principais fatores determinantes do metabolismo de indução ao florescimento da cultura (ALEXANDER, 1973). Acanade-açúcar é uma planta que floresce somente quando submetida a dias com comprimentos inferiores a um fotoperíodo crítico, sendo, portanto, uma planta de dia curto (PDC), de acordo com ARÉVALO et al. (1968) e SEGATO et al. (2006). Desse modo, uma variedade que floresce em um país poderá não florescer em outro (HAAG \& MALAVOLTA, 1964).

Trabalhando com o fotoperíodo, BERDING (1995) mostrou que o pendoamento em cana-de-açúcar é iniciado com a diminuição do comprimento do dia. A maioria dos trabalhos concentra-se em encontrar as características do comprimento do dia que induzem o florescimento (ABOU-SALAMA, 1990).

As melhores condições para que o florescimento aconteça são encontradas nas regiões equatoriais do globo, com pequenas variações de temperatura. Nessas condições, o florescimento pode ser induzido em qualquer época do ano, sendo o fotoperíodo ideal de 12 a 12,5 horas para ocorrer a indução floral em cana-de-açúcar (ARCENEAUX, 1967; CLEMENTS \& AWADA, 1967). Por outro lado, em latitudes maiores, o florescimento é sazonal, ocorrendo, principalmente, quando o fotoperíodo diminui, isto é, quando as plantas estão concluindo o período vegetativo (RODRIGUES, 1995). Na comparação de características climáticas essenciais para que ocorra o florescimento na cana-de-açúcar, SILVA PIRES et al. (1984) verificaram que, na região Nordeste, ocorre um fotoperíodo favorável muito mais prolongado do que nas condições do Estado de São Paulo.

Para que a indução floral ocorra adequadamente sob condições normais, é preciso um período de crescimento vegetativo vigoroso da canade-açúcar (ETHIRAJAN, 1987), pois, para a formação da panícula, há utilização de açúcares armazenados anteriormente, com consequente chochamento da parte superior do colmo. Já em estudos que avaliam o efeito da idade da planta e de tratamentos fotoindutivos na floração da cana-de-açúcar, VIVEIROS et al. (1991) verificaram que as plantas que tinham três, quatro, cinco e seis meses de idade floresceram, ao iniciar-se o tratamento fotoindutivo com iluminação artificial. IAIA et al. (1985), avaliando os efeitos do florescimento nas variedades NA56-79, SP70-1143 e IAC48-65, utilizaram a iluminação noturna para inibir o florescimento de plantas de cana-de-açúcar da mesma idade, e essa interrupção do período escuro inibiu totalmente o florescimento.

\section{Temperatura}

A grande variabilidade do índice de florescimento, de acordo com PEREIRA (1985), nas condições paulistas, evidencia que o fotoperíodo não é o único fator controlador do fenômeno, tendo importância também a temperatura. Esta ganha maior relevância na medida em que se distancia da linha do Equador. Alguns pesquisadores destacam que as temperaturas noturnas têm maior influência no florescimento, normalmente aquelas abaixo de $18^{\circ} \mathrm{C}$ por períodos maiores do que 10 dias (CASTRO, 2001).

Nos locais onde ocorre florescimento profuso, a temperatura mínima raramente fica abaixo de 
$18^{\circ} \mathrm{C}$, e a máxima nunca ultrapassa os $32-35^{\circ} \mathrm{C}$ (LEVI, 1983). Temperaturas mínimas abaixo de $18^{\circ} \mathrm{C}$ (PALIATSEAS, 1963) e máximas acima de $31^{\circ} \mathrm{C}$ (ELLIS et al., 1967; JULIEN et al., 1974) atrasam a iniciação floral e o desenvolvimento das panículas, bem como diminuem o número de panículas formadas (CHU \& SERAPION, 1971). BERDING \& MOORE (2001) relataram que dias com temperaturas máximas maiores que $32^{\circ} \mathrm{C}$ durante a iniciação floral são deletérias para o processo do florescimento. De uma maneira geral, temperatura moderada em Poaceae aumenta o tamanho das inflorescências (RYLE \& LANGER, 1963; HEIDE, 1982). Pequenas variações na temperatura do ar podem provocar grandes mudanças no florescimento e na fertilidade do pólen. No Havaí, observou-se que é possível evitar o processo, variando a temperatura em $\pm 5^{\circ} \mathrm{C}$ (HAAG \& MALAVOLTA, 1964).

Latitude

A latitude exerce forte efeito na intensidade do florescimento. ALEXANDER (1973) elaborou uma escala para o florescimento da cana-de-açúcar, propondo o início deste durante o primeiro mês após o equinócio outonal, nas regiões entre 10 e 15ํㅡㄹ durante o segundo mês entre 20 e 25ำ e durante o terceiro mês entre 25 e $30^{\circ}$ de latitude. Essa correlação positiva entre as menores latitudes e a precocidade da formação da gema floral é destacada por outros autores, os quais observaram que, em ambientes tropicais, como Sudão $\left(13^{\circ} 05^{\prime} \mathrm{N}\right)$ e Malavi $\left(12^{\circ} 30\right.$ 'S $)$, o florescimento em canade-açúcar se dá em 80 a 100\% das plantas. No entanto, em regiões subtropicais, como o Sul da África $\left(25^{\circ} 22^{\prime}\right.$ para $30^{\circ} 30^{\prime} \mathrm{S}$ ), o florescimento ocorre esporadicamente, e a incidência não é alta (DONALDSON \& SINGELS, 2004).

No Brasil, são poucos os lugares privilegiados para que ocorra o florescimento natural da cana-de-açúcar, com formação de sementes viáveis de interesse para os programas de melloramento genético. Dessa forma, destaca-se a região litorânea do Estado de Alagoas, onde é a base para a obtenção de novas variedades de cana-de-açúcar da sigla RB, a qual atende à RIDESA (Rede Interuniversitária para Desenvolvimento do Setor Sucroalcooleiro), assim como da sigla $\mathrm{CV}$, que pertence à Canavialis. O litoral do Estado da Bahia também sedia as plataformas de cruzamentos de outras duas instituições, a do Centro de Tecnologia Canavieira, que desenvolve as variedades CTC, e a do programa de melhoramento do Instituto Agronômico de Campinas, que seleciona as variedades IAC.

O florescimento da cana-de-açúcar nessa região de Alagoas, por exemplo, geralmente, inicia-se no mês de janeiro e se estende até o final de junho (SANTOS, 2005). Uma avaliação do período de florescimento para 200 genótipos, entre os anos de 1998 a 2004, indicou que $7 \%$ florescem entre 8 e 30 de abril; 56,5\% florescem entre os dias 1 e 12 de maio; $34,5 \%$ florescem entre os dias 13 e 26 de maio; e 1,5\% florescem após 26 de maio. BARRETO et al. (2002) afirmam que as hibridações na Serra do Ouro (AL) começam em abril e se estendem até a terceira semana de junho.

Umidade

A existência de um período seco, na época da indução do florescimento, pode prejudicar esse processo fisiológico (BERDING, 1995). A deficiência hídrica pode reduzir a intensidade de pendoamento da cana-de-açúcar em solos nativos (YEU, 1980; PEREIRA et al., 1983). Pesquisadores mostraram que, em áreas onde o fotoperíodo e a temperatura raramente inibiam o florescimento na cana-de-açúcar, a variação da intensidade de florescimento entre alguns anos foi resultado de oscilações nas precipitações anuais (MOORE, 1987). Em outro trabalho, PANJE \& SRINIVASAN (1960) constataram um atraso de 14 dias na floração dos clones estudados de Saccharum spontaneum quando, no período indutivo, a precipitação foi de apenas $74 \mathrm{~mm}$.

Logo, uma técnica de sucesso no Havaí é suspender a irrigação no período de indução floral da cultura. Com o estresse hídrico na cana-de-açúcar, é possível evitar o florescimento e promover aumentos no rendimento em cerca de $10 \%$ (HUMBERT, 1974). No entanto, a prevenção do florescimento pelo manejo da água só pode ser utilizada em regiões onde ocorrem verões e outonos pouco chuvosos, o que pode tornar esse método impraticável em muitas regiões. Dessa forma, a adequada umidade do solo é crítica para a indução floral, para o desenvolvimento da inflorescência, para a definição do momento da emergência e para a produção de sementes na fase reprodutiva da cultura (MOORE \& NUSS, 1987).

\section{Nutrientes}

Dentre os minerais, deve ser destacado o nitrogênio, por seu envolvimento com o florescimento. De acordo com HUMBERT (1974), altas doses de nitrogênio alteram a relação carbono/nitrogênio, diminuindo o florescimento, assim como os demais minerais também têm relações com o florescimento na cana-de-açúcar.

Um crescimento vigoroso da cana-deaçúcar antes da indução é preciso para se obter o máximo florescimento na cultura. Entretanto, doses altas 
de nitrogênio, especialmente no momento da indução, diminuem o florescimento (BURR, 1950; STEVENSON, 1965; ALLAM et al., 1978). BERDING et al. (2004) demonstraram que o dobro da dosagem de nitrogênio reduziu a emergência das panículas. Em Edgecombe Mount, no Sul da África, o florescimento foi reduzido por 25 dias em razão da quantidade excessiva de nitrogênio no solo (NUSS \& BERDING, 1999).

Além de doses altas de nitrogênio, as doses baixas podem afetar também a intensidade do florescimento, o tamanho da flor e a produção de sementes (BRUNKHORST, 2001). Entretanto, o nitrogênio é necessário em quantidade ótima, mas essa quantidade de fertilizante por genótipo de cana-deaçúcar, para facilitar o florescimento nos programas de melhoramento, é ainda desconhecida (LABORDE, 2007). BERDING \& MOORE (2001) questionam o conhecimento da interação entre nutrição e processo de florescimento em cana-de-açúcar.

A manutenção do regime constante de nutrição mantém melhor a fase reprodutiva, a fase de desenvolvimento e a fase de emergências das panículas de cana-de-açúcar, de acordo com BRUNKHORST (2001) e BRUNKHORST (2003). O papel e o manejo do nitrogênio ainda requerem maiores atenções.

Em relação ao fósforo, a quantidade ótima requerida para um adequado crescimento da cana-deaçúcar é de 3-5g kg-1 de matéria seca de planta durante o estádio vegetativo. A probabilidade de toxicidade com fósforo aumenta com quantidades maiores que $10 \mathrm{~g} \mathrm{~kg}^{-1}$ de matéria seca (BELL et al., 1990).

No que concerne ao potássio, HUMBERT (1974) observou que o comportamento da cana-deaçúcar tem variado em relação à variedade utilizada. Doses altas de potássio aumentam o índice de florescimento da variedade H42-8596, mas diminuiu para a variedade H38-2915 e outras variedades não mostraram qualquer sensibilidade.

Fatores internos

O estímulo indutivo

Ainda são poucos conhecidos os processos pelos quais ocorre a iniciação floral (RUIZGARCIA et al., 1997). Os mecanismos moleculares começaram a ser estudados somente nos últimos anos (KOBAYASHI et al., 1999). Porém, sabe-se que a transição da fase vegetativa para a reprodutiva resulta de uma interação de sinais endógenos com sinais do meio ambiente (LEVY \& DEAN, 1998). As baixas temperaturas e o fotoperíodo seriam os fatores do ambiente mais importantes (KANIA et al., 1997), e dentre os sinais endógenos há destaque para o papel das giberelinas.
Atualmente, sabe-se que o fitocromo do tipo I (phy A) é estimulador da floração e que o tipo II (phy B, C, D, E, F) é inibidor. Desse modo, em Arabidopsis, mutantes sem phyA possuem florescimento retardado e mutantes sem phyB possuem florescimento acelerado. Uma das hipóteses é de que phyA seria um inibidor de uma substância (hormônio), que, por sua vez, inibiria a floração. É importante ressaltar que, embora a resposta fotoperiódica seja percebida na folha, a resposta da floração ocorre no ápice caulinar. Tal distribuição espacial requer a presença de substâncias inibidoras ou estimuladoras, capazes de serem translocadas. Experimentos de enxertia confirmam a presença de tais substâncias. Esses experimentos levaram alguns pesquisadores, ainda na década de 30 , a postularem a existência do florígeno. Muitas tentativas, sem sucesso, de isolar e caracterizar esse hormônio hipotético têm sido realizadas no intuito de compreender os mecanismos de interação com fitocromos (CASTRO et al., 2005).

Alguns candidatos a florígeno apareceram ao longo de décadas, mas nenhum deles conseguiu perfazer todos os requisitos esperados. Como a aplicação de giberelina é capaz de promover a floração em plantas de dias longos (PDL) mantidas em condições de dias curtos (DC), ela tem sido uma candidata a florígeno. Análises genéticas têm demonstrado que existem genes específicos envolvidos na indução floral. Um desses genes é o LEAFY, o qual foi isolado em mutantes de Arabidopsis. A constatação de que a giberelina induz o gene LEAFY em Arabidopsis reforça a ideia de que esse hormônio é importante para a floração em algumas espécies vegetais, mas é pouco provável que seja o florígeno. Recentemente, foi demonstrado que mRNAs são capazes de se translocarem via floema e alterar o programa de desenvolvimento do ápice caulinar. Tal experimento leva à hipótese de que o chamado florígeno poderia ser o mRNA de um gene estimulatório da floração, assim como o gene LEAFY (CASTRO et al., 2005).

\section{Efeitos da giberelina (GA)}

Dentre os hormônios vegetais que têm sido aplicados para induzir o florescimento, somente as giberelinas têm demonstrado capacidade para promover a formação de primórdios florais em condições naturais não indutivas (ARTECA, 1996).

A GA aplicada em uma planta no estádio vegetativo pode ativar a sua transformação ao estádio floral, estimulando o mecanismo indutivo de plantas de dias longos (PDL). Inúmeros trabalhos mostram que a GA inibe o florescimento em plantas de dias curtos (PDC). ALEXANDER (1973) demonstrou que a GA 
inibiu o florescimento em cana-de-açúcar. Acredita-se que a GA endógena seja quantitativamente reduzida, pelas substâncias florais produzidas na fase do florescimento. Monitorando os ápices de cana-deaçúcar (Saccharum spp. Híbrido), MOORE (1987) descobriu que o ápice floral contém de oito a nove vezes mais porcentagem de iso-GA $\mathrm{G}_{3}$ que os ápices vegetativos e reduzida quantidade das $\mathrm{GA}_{19}$ e $\mathrm{GA}_{36}$.

Efeitos da radiação vermelha e vermelha extrema

O fitocromo está envolvido diretamente com as respostas fotoperiódicas. Normalmente, existem duas formas de fitocromo, uma delas instável, mas fisiologicamente ativa, a forma FVE (fitocromo vermelho extremo), e a forma estável, mas fisiologicamente inativa, a FV (Fitocromo vermelho) (RODRIGUES, 1995).

Logo, em condições de luz, a forma predominante do fitocromo é a FVE e, no escuro, a FV. FV não tem atividade fisiológica em induzir o florescimento, apenas FVE. Assim, para a indução do florescimento da cana-de-açúcar, há a necessidade de baixas concentrações de FVE, o que consegue-se caso não haja iluminação por luz vermelha ou branca, no período noturno, até atingir a quantidade de horas mínimas de escuro, em torno de 11,5 horas para a cultura. Caso haja qualquer iluminação, a concentração de FVE eleva-se imediatamente, quebrando o estímulo (RODRIGUES, 1995).

\section{Efeitos do florescimento na cana-de-açúcar}

O florescimento da cana-de-açúcar é um estádio de desenvolvimento da cultura desejável para os programas de melhoramento genético, porém indesejável para o cultivo comercial, pois acarreta grandes prejuízos. Os danos consequentes do florescimento são ocasionados pelo consumo do açúcar pela respiração, utilizando o açúcar para a formação das panículas ao invés de armazenar na forma de sacarose nos colmos. Esse consumo de sacarose provoca a perda de água dos entrenós, ocorrendo o fenômeno conhecido por isoporização (ou chochamento) da cana-de-açúcar, no sentido do topo para a base (SEGATO et al., 2006).

Outras mudanças fisiológicas acontecem, como mudanças na distribuição da água, redistribuição de nutrientes orgânicos e inorgânicos, diminuição nas reservas de carboidratos em função da isoporização que aparece após o florescimento (LOEHWING, 1953) e excreção de potássio e nitrogênio pelo sistema radicular (LAVANHOLI, 2001).

A intensidade do processo de florescimento e as consequências na qualidade da matéria-prima variam com a variedade e com o clima. A redução do volume de caldo é o principal fator no qual o florescimento interfere (AZEVEDO, 1981), resultante do aumento do teor de fibras e, consequentemente, elevando a produção de bagaço. IAIA et al. (1985) observaram que as variedades SP 70-1143 e IAC 48-65 apresentaram altos teores de fibra quando floresceram. Nessas variedades de cana-de-açúcar que florescem facilmente, os internódios superiores contêm maior teor de fibra. A porcentagem de fibra nos seis internódios superiores é $14 \%$ maior nas plantas floridas do que nas que não floresceram (AZEVEDO, 1981).

\section{Idade da cultura no período de florescimento}

De acordo com MANGELSDORF (1953), há diferença na resposta dos diferentes genótipos em relação ao florescimento na fase juvenil da cana-deaçúcar. Com a paralisação do crescimento da cana-deaçúcar florescida, para a cana-de-ano (ciclo de 12 meses), o florescimento em junho diminuiu a possibilidade de haver mais entrenós (apenas cerca de quatro), até os meses de setembro, outubro e novembro, épocas em que essa cultura é normalmente colhida. Assim, os prejuízos são mais elevados que os causados à cana-de-ano e meio (ciclo de 18 meses), a qual pode ser colhida mais no início da safra (RODRIGUES, 1995).

Quando o florescimento ocorre de quatro a oito meses antes do período de colheita da cana-deaçúcar, compromete a produtividade e, consequentemente, a sacarose produzida por unidade de cana colhida (CASTRO, 2001). Experimentos realizados por HUMBERT (1974), na Ewa Plantation Company, no Havaí, mostraram que 35\% de floração reduzem de seis a sete toneladas de cana ha-1.

Em estudo de comportamento de clones e variedades de cana-de-açúcar, foi avaliada a ocorrência de florescimento e isoporização em cana-planta e canasoca. SORDI \& BRAGA JUNIOR (1996) verificaram que, em média, o florescimento foi ligeiramente maior nas condições de cana-planta do que nas condições de cana-soca.

\section{Controle do florescimento}

Inúmeros métodos têm sido utilizados visando a controlar o florescimento, incluindo desde a interrupção do período escuro por iluminação artificial e passando por controle de temperatura, suspensão da irrigação, defoliação mecânica e pulverização de substâncias químicas. Qualquer desses métodos pode ter sucesso, suprimindo o florescimento, desde que aplicado durante o período crítico da indução floral. Desses métodos, os mais práticos são o controle hídrico e o uso de reguladores vegetais. O florescimento 
da cana-de-açúcar também pode ser reduzido pela utilização de cultivares com baixo potencial de florescimento (RODRIGUES, 1995).

A utilização de traumatismos fisiológicos para obter o retardamento do florescimento foi estudada por MACHADO JR. et al. (1989), com o objetivo de verificar o sincronismo entre variedades de florescimento precoce e tardio para fins de cruzamento. Esses pesquisadores verificaram que flashes de iluminação no período noturno, corte do palmito acima da gema apical e diminuição da superfície foliar retardam o florescimento.

\section{Controle do florescimento por reguladores vegetais}

Evitar a iniciação floral por meio da aplicação de reguladores químicos pode ser de interesse econômico em diversas regiões do Brasil, onde cultivares com alto potencial de inflorescência estão sendo plantadas em áreas de baixa altitude, sem irrigação e dependentes da precipitação local.

Vários compostos têm sido e estão sendo utilizados no controle do florescimento. Na Índia, inicialmente, utilizava ANA (ácido naftaleno-acético), nitrato de cobalto, catecol, hidroquinona e pentaclorofenol, sendo os melhores resultados obtidos com o pentaclorofenol. Os outros reguladores vegetais inibiram o florescimento em 30 a 60\%, e múltiplas aplicações eram mais efetivas que uma única aplicação (RODRIGUES, 1995).

A Hidrazida maleica $(\mathrm{MH})$, adicionada à giberelina, proporcionou total inibição do florescimento na Austrália, e nenhum dos dois reguladores inibiu o florescimento quando aplicado de forma isolada. O diquat tornou-se o produto mais amplamente utilizado como inibidor químico da florescência no Havaí (RODRIGUES, 1995). O produto mostrou-se parcialmente eficiente em evitar a florescência da canade-açúcar, em razão da ocorrência de danos relativamente extensos ao dossel da cultura, por um período de três meses.

Experimento realizado no Havaí comparando etefon e diquat, nas cultivares 'H 70-0144', 'H 61-1721' e 'H 62-4761', mostrou ser o ethephon mais eficiente que o diquat no controle da florescência da cana-deaçúcar. O etefon foi mais eficiente em um amplo espectro de períodos para o controle floral e não atuou como um dessecante do dossel da cultura da cana-deaçúcar(RODRIGUES, 1995).

Em estudo com diversos produtos para o controle do florescimento da cana-de-açúcar, foi verificado que quatro produtos apresentaram uma taxa muito boa de controle de florescimento da variedade IAC48-65, destacando-se fluazifop-butil (125g i.a. ha-1), com $100 \%$ de controle, ethephon (480g i.a. ha-1), glifosate (240g i.a. ha ${ }^{-1}$ ) e paraquat ( 100 g i.a. ha-1), com menor controle do florescimento (LEE et al., 1985).

A habilidade do etefon em prevenir o florescimento é extremamente importante em culturas agrícolas, principalmente em cana-de-açúcar, quando o florescimento causa um decréscimo do benefício econômico e, consequentemente, queda do teor de sacarose (NICKELL, 1982). CALÇA et al. (1984) observaram que as parcelas tratadas com etefon não apresentaram florescimento, enquanto que nas não tratadas houve grande indução ao florescimento em seus experimentos.

Benefícios com o suprimento do florescimento através do etefon foram obtidos no Sudão (HARDY et al., 1986), Havaí (MOORE \& OSGOOD, 1986) e na Nigéria. Por meio de observações da produção da cana-de-açúcar, sugere-se que os ganhos podem ser obtidos até seis meses após a iniciação do florescimento no Sul da África, com o uso do etefon.

Brasil e Malavi também têm utilizado o etefon em escala comercial (HARDY et al., 1986). COLETI et al. (1986), trabalhando no Brasil, não encontraram benefícios com o etefon quando a incidência do florescimento era de 36\%. No Sul da África, também não foi encontrado benefício com o uso do etefon na variedade N23, quando a incidência de florescimento foi de 45-48\% (DONALDSON, 1996).

Em experimento de LEE et al. (1985), o ethephon foi o único produto que apresentou efeitos positivos em todos os caracteres analisados (florescimento, chochamento, número de internódios/ cana e peso/cana), comparando-se com a aplicação de fluazifop butil, glifosate, etefon e paraquat. Em estudo com aplicação de etefon na quarta semana de fevereiro de 1988, SILVA et al. (1989) obtiveram maiores produtividades nas áreas tratadas em razão da diminuição do florescimento e emissão da panícula, em relação a SP70-1143 não tratada. O florescimento e a isoporização foram completamente inibidos pela aplicação de etefon.

A eficiência do uso do etefon (480g i.a. ha-1) para a melhoria da qualidade da matéria-prima, na Usina Quatá (SP), foi verificada por SALATA et al. (1992). Em aplicações tardias de etefon, obteve-se $40 \%$ de inflorescência, 6,1\% de isoporização e 90,7 de TCH, enquanto nas parcelas não tratadas obteve-se: $62 \%$ de florescimento, 13,5\% de isoporização e 89,7 de TCH. No mesmo sentido, o experimento realizado por LAVANHOLI (2001), para inibição do florescimento da cana-de-açúcar, obteve uma redução de 56\% com a aplicação de etefon. 
Recentemente, CAPUTO et al. (2007) avaliaram a eficácia de etefon e sulfometuron-metil na maturação, no florescimento, na isoporização e na produtividade de sete genótipos de cana-de-açúcar. Identificaram respostas diferenciadas dos genótipos em relação aos maturadores, no sentido que, entre aqueles que floresceram e isoporizaram, apenas houve controle total desses fatores no SP80-1842, enquanto no IAC87-3396 houve controle total do florescimento e parcial da isoporização, com maior eficiência para o sulfometuron-metil. Por outro lado, houve controle parcial e semelhante do florescimento pelos dois produtos no genótipo IAC89-3124, porém a isoporização foi mais bem controlada pelo etefon.

Pesquisas realizadas têm relatado o produto químico sulfometuron-metil, grupo químico sulfonilureia, quanto ao potencial efeito maturador em variedades de cana-de-açúcar, não havendo prejuízos à produção de cana-de-açúcar e sobre as características agronômicas da cultura. Os resultados obtidos indicam consistência no incremento na pol \% cana, no Brix e na redução do florescimento e do índice de isoporização (PONTIN, 1995; CAPUTO et al., 2007).

A segunda quinzena do mês de fevereiro, de acordo com BARBIERI et al. (1984), é a mais indicada para a aplicação de reguladores químicos na cana-deaçúcar, para as latitudes do Estado de São Paulo, o que está de acordo com DEUBER \& IRVINE (1987), os quais afirmaram que a melhor época para a aplicação está entre 20 e 25 de fevereiro, próximo do período de indução floral.

Enfim, dependo das condições, o florescimento da cana-de-açúcar pode tornar bastante prejudicial nas áreas de cultivo. Dessa forma, torna-se de grande importância a realização de mais estudos para o controle do florescimento na cultura.

\section{CONCLUSÃO}

Em áreas comerciais de produção de canade-açúcar, onde há condições ideais para o florescimento da cultura, é recomendado o uso de variedades com potencial menos ou não florífero. Quando não é possível esse manejo varietal, o uso de produtos inibidores do florescimento é a melhor alternativa, visto que as perdas com a inversão da sacarose para formação da panícula, durante o florescimento, são enormes.

\section{REFERÊNCIAS}

ABOU-SALAMA, A.M. Sugarcane pollen viability and seed setting as affected by daylength decline rates and relative humidity. Dissert Abstr Int B Sci Eng, v.52, n.3, p.11348, 1991.
ALLAM, A.I. et al. Effect of nitrogen and moisture on sugarcane flowering. Proc Int Soc Sugar Cane Technol, v.16, p.875882, 1978.

ALEXANDER, A.G. Sugarcane physiology. Amsterdam: Elsevier, 1973. 752p.

ARÉVALO, R.A. et al. Mejoramento varietal. Obtencion de nuevas variedades por via sexual. Memoria anual, estación experimental agrícola de Tucumán, n.30, p.45-59, 1968.

ARCENEAUX, G. Flowering of sugarcane. In: CONGRESS OF THE INTERNATIONAL SOCIETY OF SUGAR CANE TECHNOLOGISTS, 12., 1965, San Juan. Anais... Amsterdam: Elsevier, 1967. p.780-784

ARTECA R.N. Plant growth substances: principles and applications. New York: Chapman \& Hall, 1996. 332p.

AZEVEDO, H.J. Fisiologia da cana-de-açúcar. Araras: Programa Nacional de Melhoramento da Cana-de-açúcar, 1981. 108p. (Apostila).

BARBIERI, V. et al. Florescimento da cana-de-açúcar e suas implicações no manejo agrícola. In: CONGRESSO NACIONAL DA STAB, 3., 1984, São Paulo. Anais... São Paulo: STAB, 1984. p.273-275.

BARRETO, E.J.S. et al. Florescimento de genótipos de canade-açúcar e hibridações realizadas na Serra do Ouro-AL de 1998 a 2001. In: CONGRESSO NACIONAL DA STAB, 8., 2002, Recife. Anais... Recife, 2002. p.341-348.

BELL, R.W. et al. Growth and nodulation of tropical food legumes in dilute solution culture. Plant Soil, v.122, p.249258, 1990.

BERDING, N. Improving flowering through breeding: progress and prospects. Proc Queensland Sugar Technol Assoc, v.17, p.162-171, 1995.

BERDING, N.; MOORE, P.H. Advancing from opportunistic sexual recombination in sugarcane: Lessons from tropical photoperiodic research. Proc Int Soc Sugar Cane Technol, n.24, p.482-487, 2001.

BERDING, N. et al. Tropical, managed initiation of sugarcane flowering: optimization of nonphotoperiodic variables. Proc Aust Soc Sugar Cane Technol, v.26, p.1-12, 2004. (CDROM).

BRUNKHORST, M.J.A Preliminary investigation into the effect of plant nutrient levels on sugarcane flowering. Proc South Africa Sugar Technol Assoc, v.75, p.143-150, 2001.

BRUNKHORST, M.J. Investigation into the flowering of sugarcane variety N29 grown under different nutrient regimes. Proc S Afr Sugar Technol Assoc, v.77, p.306-312, 2003. BURR, G.O. The flowering of sugar cane. Rep Hawaii Sugar Technol, v.9, p.47-49, 1950.

CALÇA, S.A. et al. Influência do ácido 2-cloroetil-fosfônico nos parâmetros tecnológicos da cana-de-açúcar (Saccharum spp.) variedade NA56-79. STAB - Açúcar, álcool e Subprodutos. v.2, n.4, p.25-28, 1984. 
CAPUTO, M.M. et al. Acúmulo de sacarose, produtividade e florescimento de cana-de-açúcar sob reguladores vegetais. Interciencia, v.32, n.12, p.834-840, 2007.

CASTRO, P.R.C. Controle da florescência da cana-de-açúcar. Álcool \& Açúcar, v.4, n.17, p.44-49, 1984.

CASTRO, P.R.C. Fisiologia da cana-de-açúcar. In: ENCONTRO CANA-DE-AÇÚCAR, 1992, São Paulo. Anais... São Paulo: Rhodia Agro, 1993. p.4-8.

CASTRO, P.R.C. Fisiologia vegetal aplicada à cana-deaçúcar. Maceió, 2001. 7p.

CASTRO, P.R.C. Manual de fisiologia vegetal: teoria e prática. São Paulo: Agronômica Ceres, 2005. 650p.

CHU, T.L.; SERAPION, J.L. Flower initiation and tassel, emergence in sugar cane. Journal Agricultural, v.55, p.101115, 1971.

CLEMENTS, H.F.; AWADA, M. Experiments on the artificial induction of flowering in sugarcane. Proc Int Soc Sugar Cane Technol, v.12, p.795-812, 1967.

COLETI, J.T. et al. Inhibition of flowering by ethephon and its influence on sugarcane quality in Brazil. Proc int Soc Sug Cane Technol, v.19, p.298-304, 1986.

DEUBER, R.; IRVINE, J.E. Controle do florescimento da canade-açúcar com aplicação de ethephon. Boletim Técnico COPERSUCAR, n.36, p.16-24, 1987.

DONALDSON, R.A. Effects of ethephon applied to two sugarcane cultivars to prevent flowering. Proc S Afr Sug Technol Ass, v.70, p.38-41, 1996.

DONALDSON, R.A.; SINGELS, A. Yields and estimated economic returns from using ethephon to suppress flowering in annually harvested sugarcane. Mount Edgecombe: Swaziland Sugar Association Technical Services, 2004. p.12.

DUNKELMAN, P.H.; BLANCHARD, M.A. Controlled photoperiodism in basic sugarcane breeding. Proc Int Soc Sugar Cane Technol, v.4, p.80-85, 1974.

ELLIS, T.O. et al. Flowering of sugarcane in reaction to maximum temperature during the induction period. In CONGRESS OF THE INTERNATIONAL SOCIETY OF SUGAR CANE TECHNOLOGISTS, 12., 1965, San Juan. Anais... Amsterdam: Elsevier, 1967. p.790-794.

ETHIRAJAN, A.S. Sugarcane hybridization techniques. In: COPERSUCAR INTERNATIONAL SUGARCANE BREEDING WORKSHOP, 1987, Piracicaba. Anais... Piracicaba-SP: Centro de Tecnologia Copersucar, 1987. p.12.

FARIAS, S.O. et al. Controle de florescimento em cana-deaçúcar através do corte no período de indução floral. In: CONGRESSO NACIONAL DA STAB, 4., 1987, Olinda, PE. Anais... Olinda: STAB, 1987. p.718-721.

HAAG, H.P.; MALAVOLTA, E. Fisiologia. In: MALAVOLTA E. et al.: Cultura e adubação de cana-de-açúcar. São Paulo: Instituto Brasileiro de Potassa, 1964. p.221-236.
HARDY, G. et al. The use of ethephon for prevention of flowering in sugarcane in Sudan. Proc int Soc Sug Cane Technol, v.19, p.305-316, 1986.

HEIDE, O.M. Effects of photoperiod and temperature on growth and flowering in Norwegian and British timothy cultivars (Phleum pratense L.). Acta Agriculturae Acandinavica, v.32, p.241-252, 1982.

HUMBERT, R.P. El cultivo de la caña de azúcar. Tradução de Alfonso Gonzalez Gallardo. México: Compañía Editorial Continental, 1974. 719p.

IAIA, A.M. et al. Efeito do florescimento no rendimento e na qualidade tecnológica da cana-de-açúcar. Brasil Açucareiro, v.3, n.4-6, p.18-25, 1985.

JULIEN, R. et al. Juvenility, senility, climate and flowering in Saccharum. In: CONGRESS OF THE INTERNATIONAL SOCIETY OF SUGAR CANE TECHNOLOGISTS, 15., 1974, Durban. Anais... Durban: Hayne \& Gibson, 1974. p.984-990

KANIA, T. et al. FPF1 Promotes flowering in Arabidopsis. The Plant Cell, v.9, p.1327-1338, 1997.

KOBAYASHI, Y. et al. A pair of related genes with antagonistic roles in mediating flowering signals. Science, v.286, p.19601962, 1999

LABORDE, C.M. Sugarcane tasseling under artificial photoperiod conditions as affected by nitrogen rate and temperature. 2007. 84f. Dissertation Submitted to the Graduate Faculty of the Louisiana State University partial fulfillment of the requirements for the degree of Doctor of Philosophy.

LAVANHOLI, M.G.D.P. Aplicação de ethephon e imazapyr como inibidores de florescimento em cana-de-açúcar (Saccharum spp, var. SP70-1143), 2001. 210f. Tese (Doutorado em produção vegetal) - Faculdade de Ciências Agrárias e Veterinárias do Campus de Jaboticabal, - UNESP, Jaboticabal, SP.

LEE, T.S.G. et al. Controle de florescimento da cana-de-açúcar através do emprego de produtos químicos. STAB - açúcar, álcool e subprodutos, v.3, n.3, p.17-21, 1985.

LEVI, C.A. Froracion de cana de azucar, determinacion de requerimentos indutivos. Revista Industrial de Tucuman, v.60, n.1, p.1-15, 1983

LEVY, Y.Y.; DEAN, C. The transition to flowering. Plant Cell, v.10, p.1973-1990, 1998.

LOEHWING, W.F. Mineral nutrition in relation to the ontogeny of plants. In: MINERAL NUTRITION OF PLANTS, 1951, Emil Truog. Anais... Emil Truog: Un. Wisconsin, 1953. p.343-358

MACHADO JR, G.R. et al. O retardamento do florescimento através de traumatismos fisiológicos. Boletim Técnico Copersucar, n.47, p.7-10, 1989.

MANGELSDORF, A.J. 'Sugarcane breeding in Hawaii'. Hawaii Plant. Rec. v.54, p.101-162, 1953. 
MOORE, P.H.; OSGOOD, R.V. Use of ethephon to prevent flowering of sugarcane in Hawaii. Proc int Soc Sug Cane Technol, v.19, p.258-262, 1986.

MOORE, P.H. Physiology and control of flowering. Copersucar International Sugarcane Breeding Workshop, p.103-128, 1987.

MOORE, P.H.; NUSS, K.J. Flowering and flower synchronization. In HEINZ, D.J. (Ed.). Sugarcane improvement through breeding. Amsterdam, The Netherlands: Elsevier, 1987. p.102-127.

MOZAMBANI, A.E. et al. História e morfologia da cana-deaçúcar. In: SEGATO, S.V. et al. Atualização em produção de cana-de-açúcar. Piracicaba: Cadernos Planalsucar. 2006. p.11-18.

NICKELL, L.G. Plant growth regulators in the sugarcane industry. In: McLAREN, J.S. (Ed.). Chemical manipulation of crop growth and development. London: Butterworth Scient, 1982. p.167-189.

NUSS, K.J.; BERDING, N. Planned recombination in sugarcane breeding: artificial initiation of flowering in sugarcane in subtropical and tropical conditions. Proc Int Soc Sugar Cane Technol, v.2, p.504-508, 1999.

PALIATSEAS, E.D. Further studies on flowering of sugar cane in Louisiana. In: CONGRESS OF THE INTERNATIONAL SOCIETY OF SUGAR CANE TECHNOLOGISTS, 11., 1962, Mauritius. Anais... Amsterdam: Elsevier, 1963. p.805-814.

PANJE, R.R.; SRINIVASAN, K. Studies in Saccharum spontaneum. A note on the flowering sequence of Saccharum spontaneum clones. In: CONGRESS OF THE INTERNATIONAL SOCIETY OF SUGAR CANE TECHNOLOGISTS, 10, 1959, Hawaii. Anais... Amsterdam: Elsevier, 1960. p.819-824.

PEREIRA, A.R. et al. Condicionamento climático da indução ao florescimento em cana-de-açúcar. Boletim Técnico PLANALSUCAR, v.5, p.5-14, 1983.

PEREIRA, A.R. Previsão do florescimento em cana-de-açúcar. Comunicação da Pesquisa Agropecuária, v.3, n.6, p.1516, 1985.

PONTIN, J.C. Avaliação de maturadores vegetais na cana-deaçúcar. Álcool \& Açúcar, n.77, p.16-18, 1995.

RODRIGUES, J.D. Fisiologia da cana-de-açúcar. Botucatu: UNESP, 1995. 100p. (Apostila).
RUIZ-GARCIA, L. et al. Different roles of flowering-times genes in the activation of floral iniciation genes in Arabidopsis. Plant Cell, v.9, p.1921-1934, 1997.

RYLE, G.A.; LANGER, R.M. Studies on the physiology of flowering of timothy (Phleum pratense L.) I. Influence of daylength and temperature on initiation and differentiation of the inflorescence. Ann Bot, v.27, p.213-229, 1963.

SALATA, J.C. et al. A utilização de Ethrel para melhoria da matéria-prima na Usina Quatá. In: ENCONTRO RHODIA CANA-DE-AÇÚCAR, 1992, São Paulo. Anais... São Paulo: s.ed., 1992. V.2, p.49-51.

SANTOS, J.M. Avaliação do florescimento de genótipos de cana-de-açúcar na Serra do Ouro de 1998 a 2004. 2005. 54f. Monografia (Graduação em Agronomia) Universidade Federal de Alagoas, Maceió, AL.

SEGATO, S.S. et al. Aspectos fenológicos da cana-de-açúcar. In: SEGATO, S.V. et al. Atualização em produção de canade-açúcar. Piracicaba: CP 2, 2006. p.19-36.

SILVA PIRES, C.E.L.E. et al. Estudo preliminar sobre a ocorrência de florescimento em cana-de-açúcar nas regiões canavieiras dos Estados de Pernambuco, Paraíba e Rio Grande do Norte. In: CONGRESSO NACIONAL DA STAB, 1984, São Paulo. Anais... São Paulo: STAB, 1984. V.3, p.344-346.

SILVA, G.M. et al. The use of ethephon to manage sugarcane varieties in different locations of the central - southern region of Brazil. In: CONGRESS OF I.S.S.C.T., 1989, São Paulo. Anais... São Paulo: USP, 1989. V.20, p.623-645.

SORDI, R.A.; BRAGA JR, R.S.L.C. Comportamento de variedades de cana-de-açúcar durante a safra, em cana-planta e soca, em relação ao ganho de peso, florescimento e isoporização. In: CONGRESSO NACIONAL DA SOCIEDADE DOS TÉCNICOS AÇUCAREIROS E ALCOOLEIROS DO BRASIL, 6., 1996, Maceió. Anais... Maceió-AL: STAB, 1996. V.6, p.238-244.

STEVENSON, G.C. Genetics and breeding of sugarcane. London: Longsmans, 1965. 25p.

VIVEIROS, V.C.A. et al. Efecto de la edad de la plnata y de diferentes tratamientos fotoinductivos en la floracion de la caña de azúcar (Saccharum sp.). Acta Agronomica, v.41, n.1/4, p.37-45, 1991.

YEU, W.K. Studies on flowering of sugar cane in the South of Haiwan, China. In: CONGRESS OF THE INTERNATIONAL SOCIETY OF SUGAR CANE TECHNOLOGISTS, 17., 1980, Manila. Anais... Makati: Metro Manila, 1980. p.1301-1306. 